\title{
Evaluating the Effectiveness of Brand Communication on Implicit and Explicit Brand Knowledge in Virtual Spaces: The Case of Sports Sponsorship Exposure in Video Games: An Abstract
}

\author{
Steffen Schmidt, Matthias Limbach, Sascha Langner, and Philipp Reiter
}

\begin{abstract}
Sports sponsorship is a core element of brand communication and one of the most effective and demanded tools in marketing. In the context of soccer, sponsorship agreements dramatically increased over the last decade in terms of deal volume. At the same time, more and more brand companies place their brand into video games, so-called in-game advertising (IGA), due to an altered media consumption pattern of especially the group of young consumers. Against that background, the current study addresses the short-term effects of IGA on consumer's implicit and explicit brand knowledge after the sponsor brand (here jersey sponsor of a soccer team) has been exposed in a video game. In order to cope with a more comprehensive brand knowledge evaluation, a wider association assessment is conducted incorporating the attitudinal and motivational value of a brand, both evaluated with regard to the processing of implicit and explicit brand associations. The presented study suggest that sponsorship communication applying IGA has a positive effect on the information processing of implicit brand associations when the video game experience was rated as positive, but not when negative. In contrast, no impact at all of IGA on an explicit level was found.
\end{abstract}

\footnotetext{
S. Schmidt $(\varangle) \cdot$ S. Langner

Leibniz University of Hannover, Hannover, Germany

e-mail: schmidt@m2.uni-hannover.de; langner@m2.uni-hannover.de

M. Limbach

Europafachakademie Dr. Buhmann, Hannover, Germany

e-mail: limbach@buhmann.de

P. Reiter

Eye Square GmbH, Berlin, Germany

e-mail: reiter@eye-square.com
} 